\title{
LOS DESAFÍOS DE LA UNIVERSIDAD EN LA SOCIEDAD DEL CONOCIMIENTO.
}

\author{
Dra. Lic. Liliana Ramírez \\ Instituto y Departamento de Geografía \\ Facultad de Humanidades-UNNE \\ Prof. Titular ordinaria Técnicas en Geografía II. \\ Investigadora Independiente-CONICET \\ E-mail: Iramirez@hum.unne.edu.ar
}

Parte de la presente contribución fue presentada en la Jornada de Trabajo Marco de referencia para el diseño de escenarios posibles de la Universidad Nacional del Nordeste: Una mirada desde la Evaluación Institucional. UNNE.SGP-SEP. Empedrado, febrero 2010.

\section{Resumen}

A lo largo de su historia la Universidad como institución ha logrado superar satisfactoriamente los grandes cambios que se sucedieron. Desde la fundación de la Universidad Nacional de Córdoba en 1613, diferentes crisis sociales, diversos modelos económicos, distintas vicisitudes políticas no han afectado, al menos en gran medida, la continuidad de las principales funciones de esta institución. Sin embargo los últimos años del Siglo XX, nos han enfrentado a un mundo sin fronteras, en el que todos somos parte de la Sociedad del Conocimiento que se encamina, de forma cada vez más evidente, hacia la Sociedad en Red. La Universidad, al igual que en otras épocas, tiene que adaptarse a estos cambios, pero ahora, con mayor celeridad para garantizar a sus graduados su inclusión en una sociedad altamente cambiante. En este aporte queremos resaltar, basándonos en algunas reflexiones de autores y en la realidad que percibimos cotidianamente, algunos desafíos que, con mayor fuerza, tendremos que enfrentar en nuestra Universidad en los próximos años.

\section{Palabras Claves}

Universidad - Sociedad del Conocimiento - Desafíos

\begin{abstract}
Throughout its history the University as institution has successfully overcome the major changes that occurred. Since the foundation of the Universidad National of Cordoba, in 1613, different social crises, various economics models, many political events have not affected, at least largely, the continuity of the principal functions of this institution. However, the last years of Twentieth Century we have faced a world without borders, in the one that everyone are part of the Knowledge Society that routes so increasingly evident, towards the Networked Society. The University, as at other times, has to adapt to these changes, but now, more quickly to ensure its graduates inclusion in a rapidly changing society. In this contribution we want stand out some challengers that most strongly we will face in our University in the coming years.
\end{abstract}

\section{Key words}

University - Knowledge Society - Challenges

Publicado en formato digital: Dra. Lic. Liliana Ramírez. LOS DESAFÍOS DE LA UNIVERSIDAD EN LA SOCIEDAD DEL CONOCIMIENTO. Revista Geográfica Digital. IGUNNE. Facultad de Humanidades. UNNE. Año 11. No 21. Enero - Junio 2014. ISSN 1668-5180 Resistencia, Chaco.

En: http://hum.unne.edu.ar/revistas/geoweb/default.htm 
Cuando miramos hacia el futuro, vemos numerosas incertidumbres sobre lo que será el mundo de nuestros hijos, de nuestros nietos y de los hijos de nuestros nietos. Pero al menos, de algo podemos estar seguros: si queremos que la Tierra pueda satisfacer las necesidades de los seres humanos que la habitan, entonces la sociedad humana deberá transformarse. Así el mundo de mañana deberá ser fundamentalmente diferente del que conocemos hoy, en el crepúsculo del siglo XX y del milenio.

Debemos, por consiguiente, trabajar para construir un "futuro viable".....

En esta evolución hacía los cambios fundamentales de nuestros estilos de vida y nuestros comportamientos, la educación -en su sentido más amplio-juega un papel preponderante. La educación es "la fuerza del futuro"; porque ella constituye uno de los instrumentos más poderosos para realizar el cambio. Uno de los desafíos más difíciles será el de modificar nuestro pensamiento de manera que enfrente la complejidad creciente, la rapidez de los cambios y lo imprevisible que caracterizan nuestro mundo

DIRECTOR GENERAL DE LA UNESCO FEDERICO MAYOR (1999) PROLOGO DE

"LOS SIETE SABERES NECESARIOS PARA LA EDUCACION DEL FUTURO"

\section{La Universidad y la Sociedad del Conocimiento}

La noción originaria de sociedad de conocimiento tiene sus orígenes en los años 1960 cuando se analizaron los cambios en las sociedades industriales y se acuñó la noción de la sociedad postindustrial. Así, por ejemplo, el sociólogo Peter Drucker pronosticó la emergencia de una nueva capa social de trabajadores de conocimiento (Drucker, 1959) y la tendencia hacia una sociedad de conocimiento (Drucker, 1969). A pesar de aquel momento inicial, tuvieron que transcurrir treinta años, y recién en la década del '90 se comienza a utilizar el término "sociedad de la información", que se utiliza, sobre todo, cuando se tratan aspectos tecnológicos y sus efectos sobre el crecimiento económico y el empleo; luego se afianza el término que nos ocupa, "sociedad del conocimiento", que tiene un uso más reciente, considerándose como punto de referencia más destacado el trabajo de Manuel Castells ${ }^{i}$. Este concepto es considerado como un cambio conceptual desde la información al conocimiento, considerándolo a éste último como principio estructurador de la sociedad moderna y resaltando su importancia para la sociedad actual, para los cambios en la estructura económica y en los mercados laborales, para la educación y para la formación. Este mismo autor, Castells, ha acuñado, a su vez, el concepto de la "sociedad red o sociedad en red" (figura 1)

Figura 1

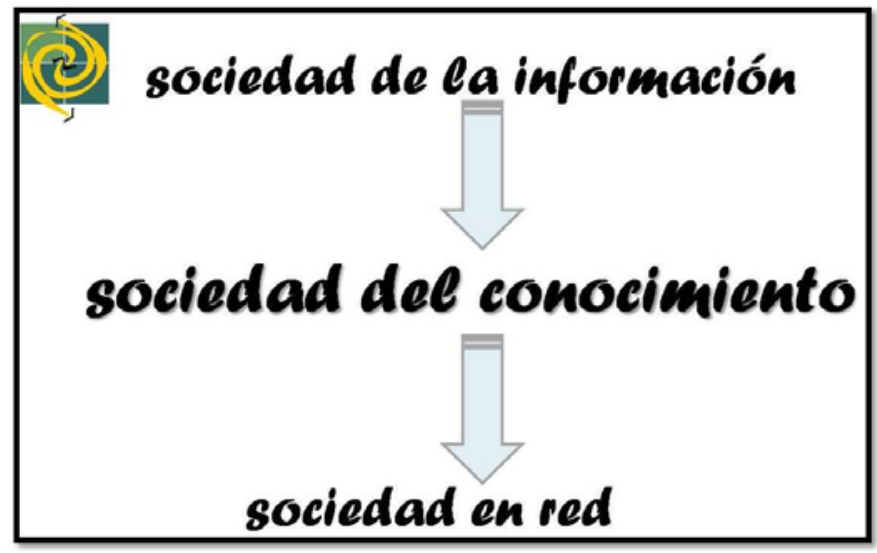

Publicado en formato digital: Dra. Lic. Liliana Ramírez. LOS DESAFÍOS DE LA UNIVERSIDAD EN LA SOCIEDAD DEL CONOCIMIENTO. Revista Geográfica Digital. IGUNNE. Facultad de Humanidades. UNNE. Año 11. № 21. Enero - Junio 2014. ISSN 1668-5180 Resistencia, Chaco.

En: http://hum.unne.edu.ar/revistas/geoweb/default.htm 
Una de las miradas sobre el concepto sociedad del conocimiento expresa la transición de una economía que genera productos a una economía basada en servicios y cuya estructura profesional está marcada por la preferencia a una clase de profesionales técnicamente cualificados (figura 2). El conocimiento teórico se ha convertido, según este enfoque, en la fuente principal de innovación y el punto de partida de los programas políticos y sociales. Este tipo de sociedad está orientada hacia el progreso tecnológico y la evaluación de la tecnología, en virtud de ella se caracteriza por la creación de una nueva tecnología intelectual como base de los procesos de decisiónii. Además está caracterizada por una estructura económica y social, en la que el conocimiento ha substituido al trabajo, a las materias primas y al capital como fuente más importante de la productividad, crecimiento y desigualdades sociales (Drucker 1994). En síntesis, resume las transformaciones sociales que se están produciendo en la sociedad moderna y sirve para el análisis de estos cambios. Al mismo tiempo, ofrece una visión del futuro para guiar normativamente las acciones políticas ${ }^{\text {iii. }}$.

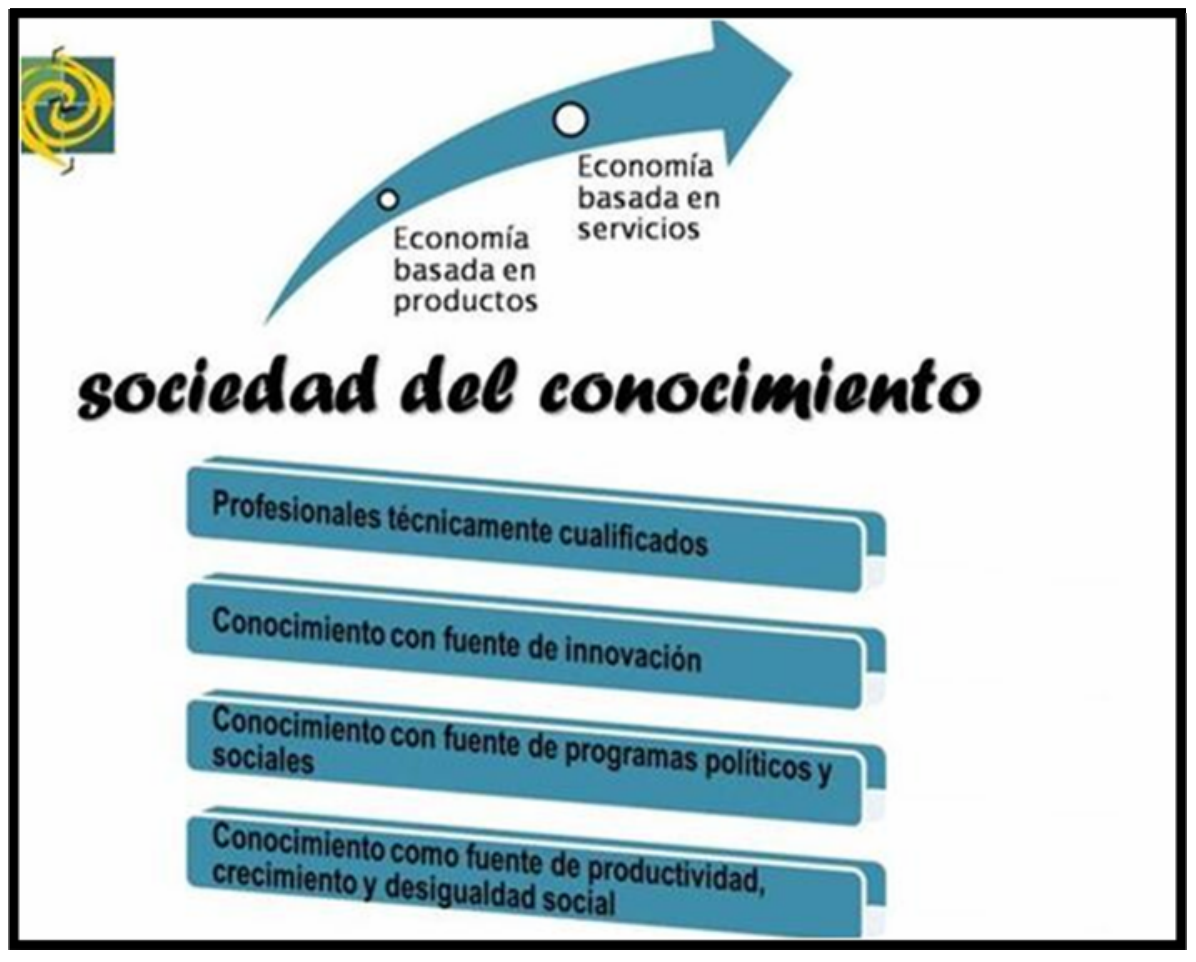

Figura 2

Esta situación genera un nuevo escenario que se caracteriza, entre otras cuestiones, por las que siguen:

- Crecimiento de la importancia relativa del sector servicios y la fuerza laboral dedicada a él;

- Cambios en el mercado, los clientes no sólo requieren de una mejor y rápida respuesta sino que están informados, tienen más poder y deben convertirse en socios tecnológicos de las empresas, involucrándose en los procesos de producción;

- Digitalización generalizada de todo tipo de información;

- Poder y difusión mundial de las Tecnologías de la Información y la Comunicación (TIC's);

- Gestión del Conocimiento, entendida como la palanca de la sabiduría colectiva para aumentar la capacidad de respuesta y la innovación;

Publicado en formato digital: Dra. Lic. Liliana Ramírez. LOS DESAFÍOS DE LA UNIVERSIDAD EN LA SOCIEDAD DEL CONOCIMIENTO. Revista Geográfica Digital. IGUNNE. Facultad de Humanidades. UNNE. Año 11. № 21. Enero - Junio 2014. ISSN 1668-5180 Resistencia, Chaco.

En: http://hum.unne.edu.ar/revistas/geoweb/default.htm 
- Virtualización y aprovechamiento de las TIC's para realizar interacciones eficaces y eficientes entre las personas a pesar de las distancias y dispersión geográfica.

Por otro lado, la sociedad del conocimiento va unida a lo que se ha conocido como la "explosión del conocimiento" que supone un aumento acelerado del conocimiento, una mayor complejidad y una rápida tendencia a la obsolescencia. Según cifras de J. Appleberry, citado por José Joaquín Brunner, el conocimiento de base disciplinaria, registrado internacionalmente, demoró 1.750 años en duplicarse por primera vez, contado desde el inicio de la era cristiana; luego, duplicó su volumen cada 150 años y después cada 50 años. Ahora lo hace cada 5 años y se estima que para el año 2020 se duplicará cada 73 días. Se estima que cada cuatro años se duplica la información disponible en el mundo; sin embargo solo somos capaces de prestar atención a entre un $5 \%$ y un $10 \%$ de esa información.

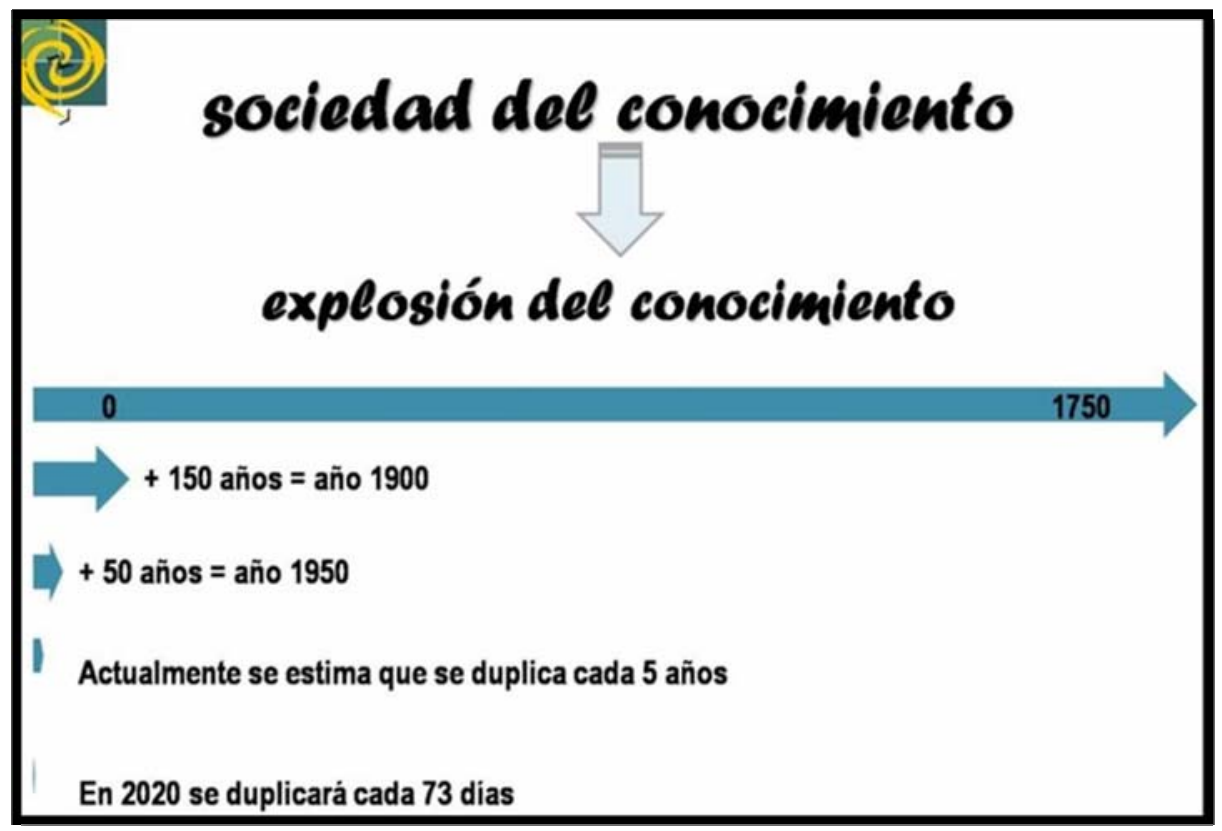

Figura 3

\section{Los desafíos que enfrenta la Universidad}

En este nuevo escenario marcado por la "sociedad del conocimiento" como contexto principal en el que las universidades tienen que desarrollar los proyectos institucionales, hemos considerado algunos desafíos que tendremos que hacer frente en los próximos años. Esta parte de la contribución tiene como sustento, al igual que el apartado anterior, relevante bibliografía, a saber:

- Los siete saberes necesarios para la educación del futuro, Edgar Morin, UNESCO, 1999.

- Desafíos de la Universidad en la Sociedad del Conocimiento, Cinco Años Después de la Conferencia Mundial sobre Educación Superior. Carlos Tünnermann Bernheim y Marilena de Souza Chaui. UNESCO, 2003

- Documento final de la Conferencia sobre Educación Superior. UNESCO, 2009

Publicado en formato digital: Dra. Lic. Liliana Ramírez. LOS DESAFÍOS DE LA UNIVERSIDAD EN LA SOCIEDAD DEL CONOCIMIENTO. Revista Geográfica Digital. IGUNNE. Facultad de Humanidades. UNNE. Año 11. No 21. Enero - Junio 2014. ISSN 1668-5180 Resistencia, Chaco.

En: http://hum.unne.edu.ar/revistas/geoweb/default.htm 
Nos situamos así en un lugar en el que la sociedad del conocimiento y la universidad forman parte de una misma realidad. La primera sostiene, además, a la sociedad de la información y a la sociedad en red, la segunda se compone de la educación presencial y de la educación a distancia. De la universidad, de sus misiones y funciones y de lo que la sociedad espera de ella, desprendemos cuatro conceptos que nos van a permitir exponer lo que, desde nuestra modesta mirada, son los cuatro principales retos que tendremos que afrontar, que no son excluyentes de otros que se puedan añadir y que a su vez, en algunos casos, ya se encuentran encaminados por lo cual el desafío concreto sería fortalecer las acciones iniciadas (figura 4).

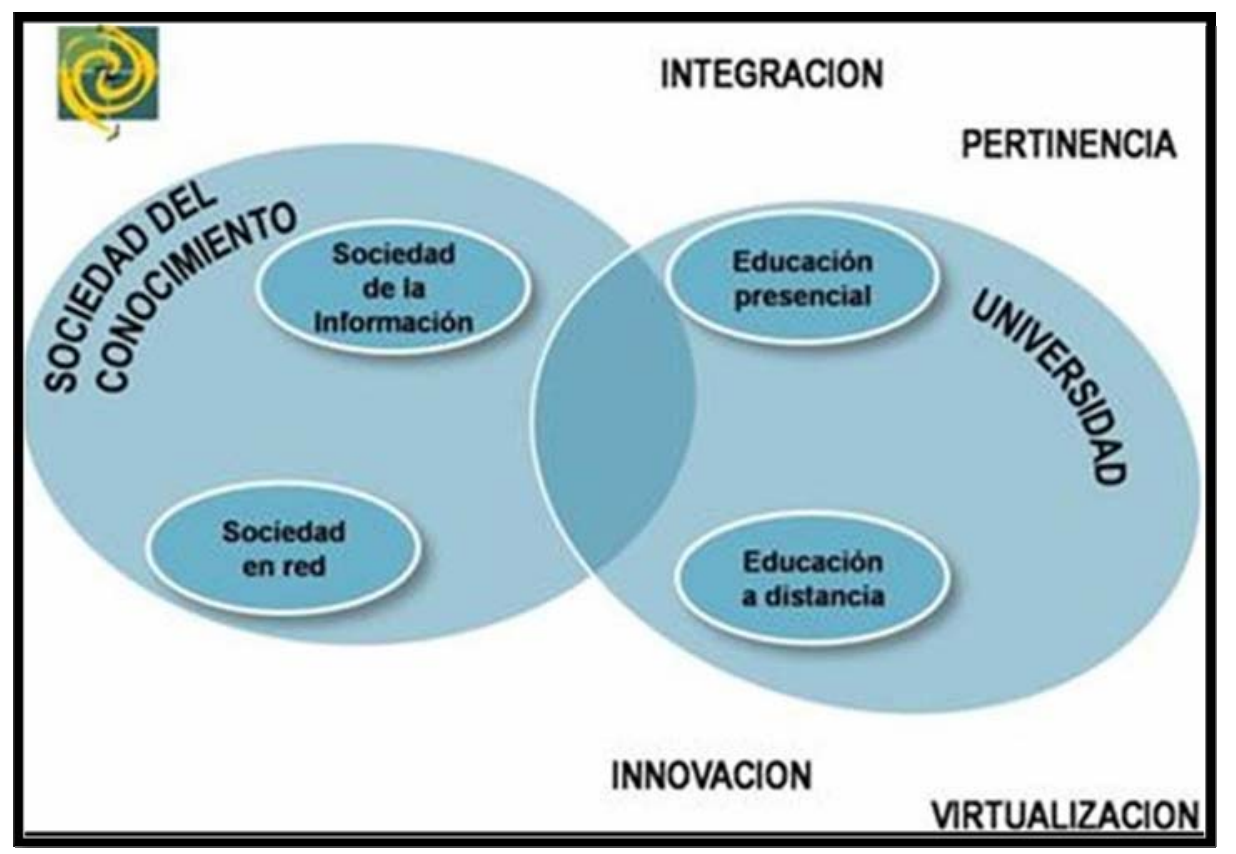

Figura 4

\section{- Internacionalización de la Universidad}

La integración nos conducirá, entre otros aspectos a la internacionalización de la universidad (figura5). En palabras de Komlavi Francisco Seddoh, Director de la División de la Educación Superior de la UNESCO "la internacionalización se ha convertido en una condición sine qua non para cumplir con el papel y la misión que le corresponde a la educación superior, como parte inherente para alcanzar la calidad y la pertinencia de la enseñanza, el aprendizaje, la investigación y el servicio a la sociedad". La internacionalización supone, entre otros aspectos:

1. Fortalecer la cooperación interuniversitaria, es decir la cooperación para el desarrollo.

2. Organizar y compatibilizar los diseños curriculares.

3. Difundir la oferta docente e investigadora en el exterior.

4. Definir las áreas geográficas de interés para la Universidad.

5. Fomentar la movilidad de los estudiantes, profesores, investigadores y personal de administración y servicios.

6. Gestionar la movilidad internacional en colaboración con los Centros, Departamentos e Institutos de origen y de destino.

7. Sistematizar la información en relación con las actividades de carácter internacional existentes, propiciando la disponibilidad de información actualizada

Publicado en formato digital: Dra. Lic. Liliana Ramírez. LOS DESAFÍOS DE LA UNIVERSIDAD EN LA SOCIEDAD DEL CONOCIMIENTO. Revista Geográfica Digital. IGUNNE. Facultad de Humanidades. UNNE. Año 11. № 21. Enero - Junio 2014. ISSN 1668-5180 Resistencia, Chaco.

En: http://hum.unne.edu.ar/revistas/geoweb/default.htm 
que permita responder eficazmente a las demandas de nuestra comunidad académica.

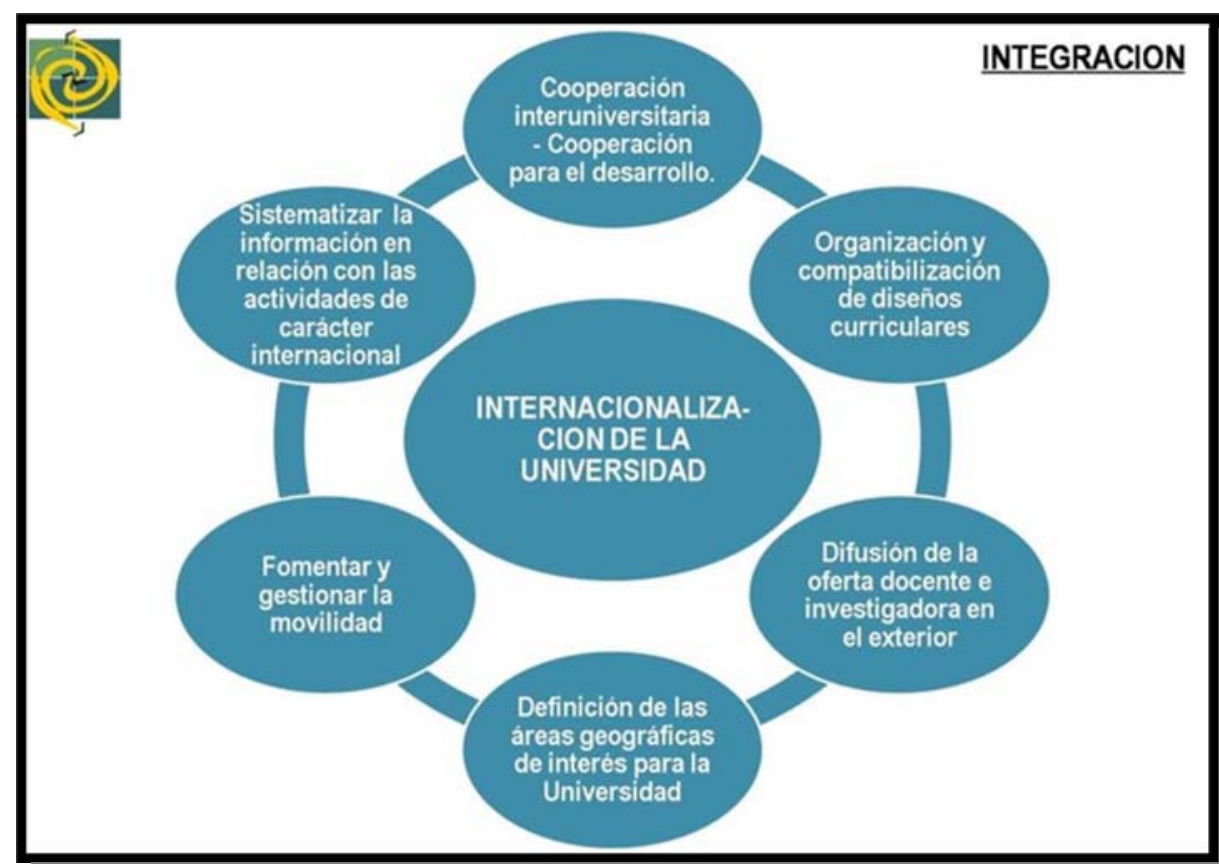

Figura 5

- Planificación de la oferta académica y su relación con las demandas sociales

La pertinencia, como ya se viene desarrollando desde la última gestión, nos seguirá orientando en la planificación de la oferta académica y su relación con las demandas sociales. Los actuales requerimientos profesionales, enmarcados en la "sociedad del conocimiento" y en la "globalización", sumados a la transformación de los modelos productivos exigen, permanentemente, una adecuación de la oferta universitaria a las demandas sociales. En este sentido la Universidad habrá de continuar revisando:

1. El grado de correspondencia entre las propuestas curriculares y las demandas sociales a los efectos de mantener la pertinencia de sus ofertas en la dinámica regional.

2. Las propuestas alternativas de transformación curricular en función de la demanda actual y potencial.

3. La formación de recursos humanos en áreas de vacancia que demandan profesionales.

Publicado en formato digital: Dra. Lic. Liliana Ramírez. LOS DESAFíos DE LA UNIVERSIDAD EN LA SOCIEDAD DEL CONOCIMIENTO. Revista Geográfica Digital. IGUNNE. Facultad de Humanidades. UNNE. Año 11. No 21. Enero - Junio 2014. ISSN 1668-5180 Resistencia, Chaco.

En: http://hum.unne.edu.ar/revistas/geoweb/default.htm 


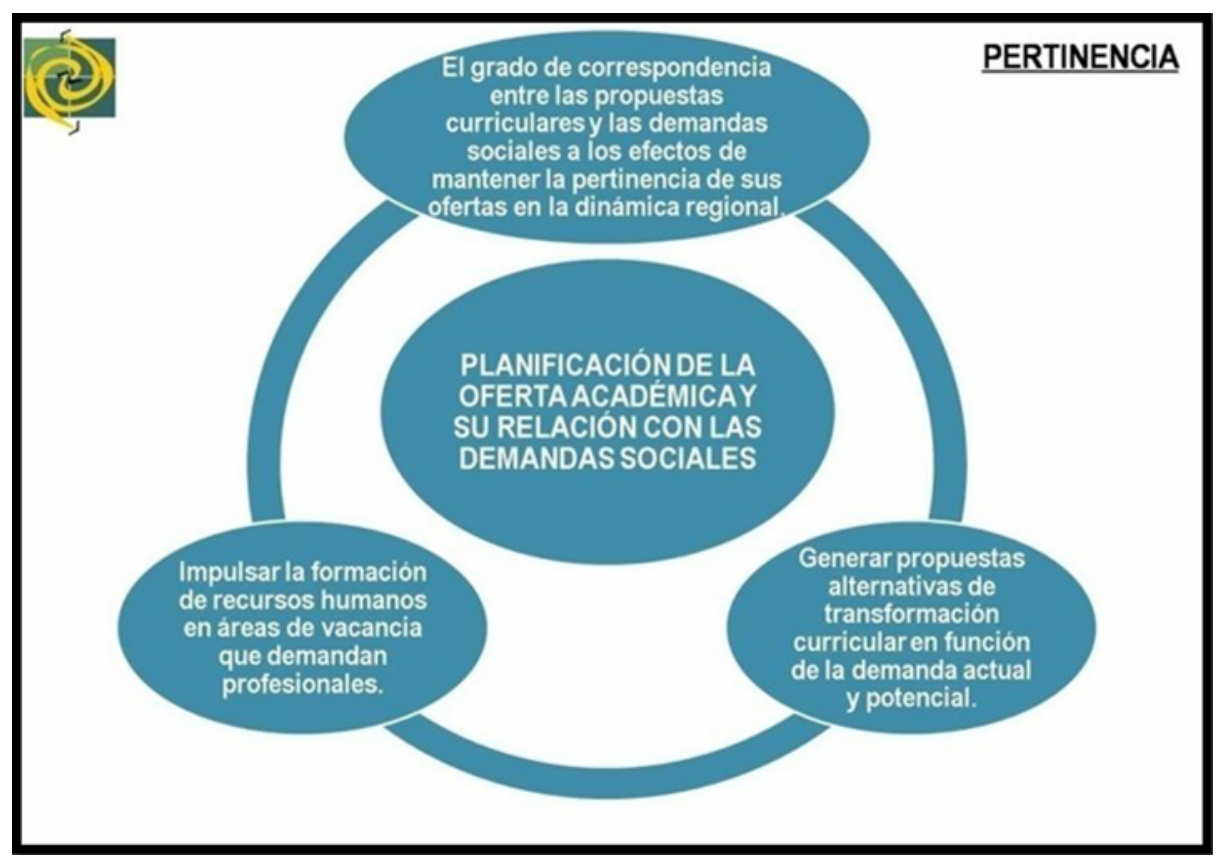

Figura 6

\section{- Expansión de la educación superior y democratización del acceso a la Educación} Superior (ES)

La virtualización nos conducirá, entre otras cuestiones a generar la expansión de la educación superior y democratización en el acceso. El pasado $1^{\circ}$ de octubre de 2009 , en la inauguración del segundo taller "Acceso y permanencia en la Educación Superior", realizado en la Universidad de Santiago de Chile en el marco de la cátedra UNESCO Inclusión a la Educación Superior, Rosa Blanco, representante de OREALC UNESCO, señaló que "Ios talentos están distribuidos de manera igual en todos los estratos socioeconómicos y culturas. Pero lo que no está distribuida por igual, son las oportunidades educativas. La expansión de la educación secundaria, las mayores exigencias del mundo productivo, la sociedad del conocimiento y la necesidad de reconversión laboral, hacen cada vez más necesario democratizar el acceso a la educación superior". Esta situación se plantea como altamente delicada en nuestro contexto regional, por ello será preciso:

1. Impulsar programas y estrategias que permitan responder a las demandas, procurando alcanzar una efectiva democratización, de manera que toda persona con los méritos suficientes tenga asegurado el acceso;

2. Organizar sistemas solidarios de apoyo a los estudiantes carentes de recursos financieros;

3. Reforzar la capacidad de las universidades para cumplir cabalmente sus funciones de docencia, investigación, extensión y servicios;

4. Diseñar estrategias que conduzcan a asegurar una educación permanente y sin fronteras durante toda la vida,

5. Consolidar procesos de descentralización y regionalización de la educación superior,

6. Generar fuertes vínculos entre las universidades y el conjunto del sistema educativo.

Publicado en formato digital: Dra. Lic. Liliana Ramírez. LOS DESAFÍOS DE LA UNIVERSIDAD EN LA SOCIEDAD DEL CONOCIMIENTO. Revista Geográfica Digital. IGUNNE. Facultad de Humanidades. UNNE. Año 11. No 21. Enero - Junio 2014. ISSN 1668-5180 Resistencia, Chaco.

En: http://hum.unne.edu.ar/revistas/geoweb/default.htm 


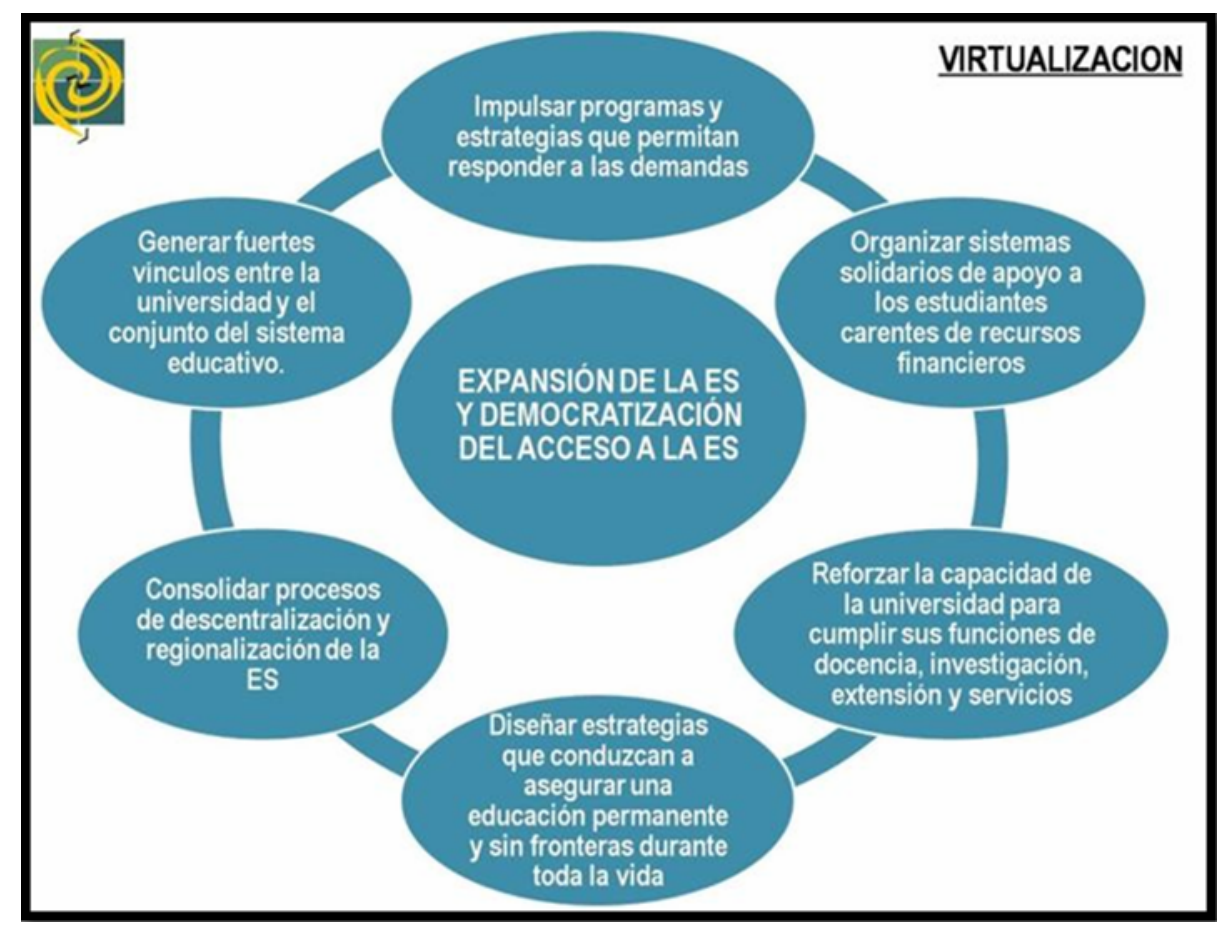

- Desarrollo del posgrado

Figura 7

La innovación nos permitirá continuar con el desarrollo del posgrado. La investigación científica, en su condición de generadora de conocimientos, juega un papel trascendente en el crecimiento económico y desarrollo social de cualquier país. A partir del desarrollo de los posgrados en nuestra Universidad se ha advertido un impulso significativo en la producción de conocimientos; no obstante, creemos que los futuros desafíos están en relación a las siguientes cuestiones:

1. Desarrollo de posgrados y producción científica en relación con la actualización, perfeccionamiento y educación continua de los graduados.

2. Desarrollo de posgrados y producción científica en relación con otros niveles del sistema.

3. Desarrollo de posgrados a través de la Educación Virtual.

Este nuevo contexto plantea un desafío altamente significativo para la Universidad Nacional del Nordeste, no se trata sólo de generar conocimientos sino de transferirlos a la sociedad. La producción de conocimientos "debe" permitir colaborar en acciones eficaces que conduzcan a una mejor sociedad en términos de calidad de vida de la población, y, paralelamente, será preciso fortalecer la presencia de la Universidad en las redes internacionales.

Publicado en formato digital: Dra. Lic. Liliana Ramírez. LOS DESAFÍOS DE LA UNIVERSIDAD EN LA SOCIEDAD DEL CONOCIMIENTO. Revista Geográfica Digital. IGUNNE. Facultad de Humanidades. UNNE. Año 11. No 21. Enero - Junio 2014. ISSN 1668-5180 Resistencia, Chaco.

En: http://hum.unne.edu.ar/revistas/geoweb/default.htm 


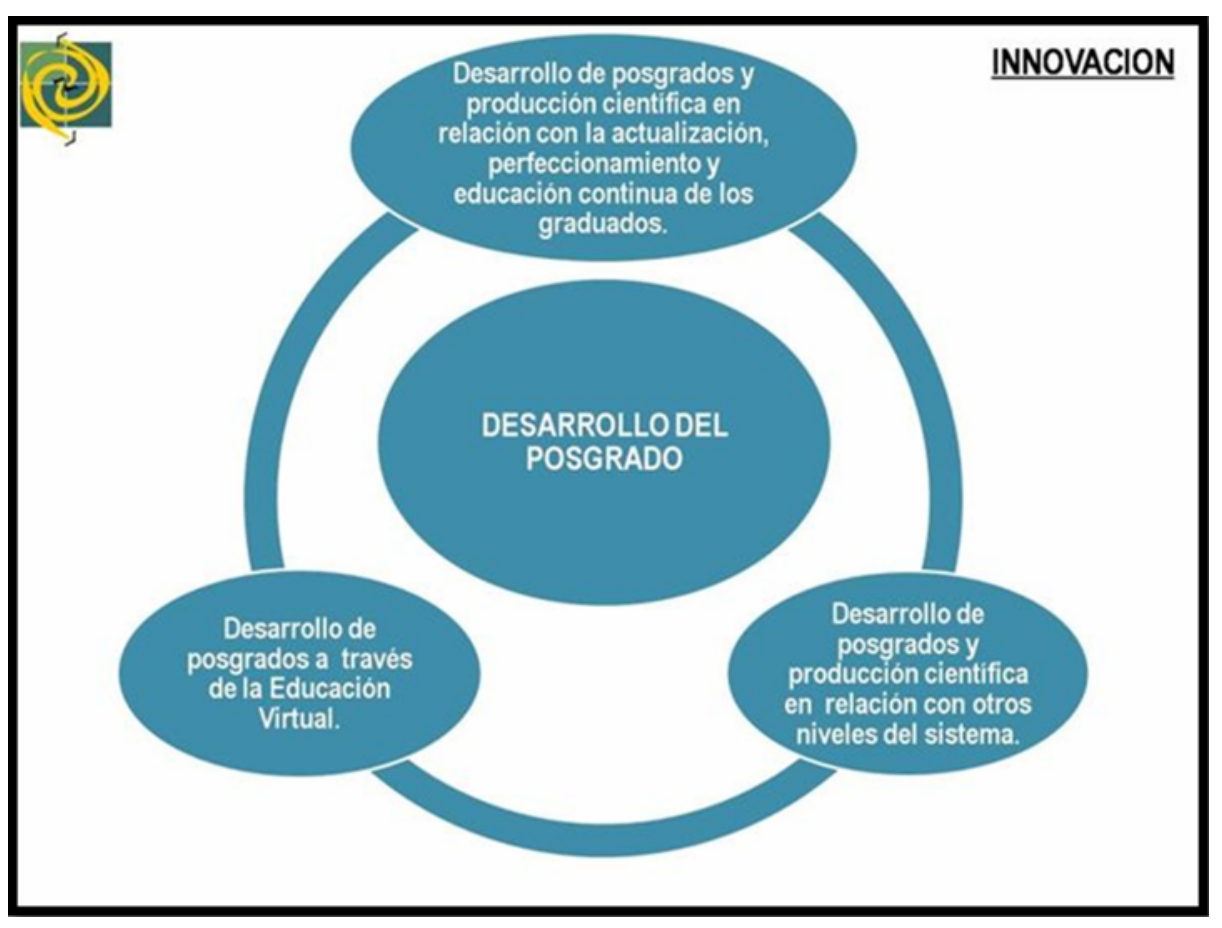

Figura 8

\section{Comentarios finales}

En el mismo prólogo elaborado por Federico Mayor en el año 1999 se lee: “Uno de los desafíos más difíciles será el de modificar nuestro pensamiento de manera que enfrente la complejidad creciente, la rapidez de los cambios y lo imprevisible que caracterizan nuestro mundo. Debemos reconsiderar la organización del conocimiento. Para ello debemos derribar las barreras tradicionales entre las disciplinas y concebir la manera de volver a unir lo que hasta ahora ha estado separado. Debemos reformular nuestras políticas y programas educativos. Al realizar estas reformas es necesario mantener la mirada fija hacía el largo plazo, hacía el mundo de las generaciones futuras frente a las cuales tenemos una enorme responsabilidad". A esta expresión generada como consecuencia de una mirada global, queremos añadir que, localmente, es necesario continuar sosteniendo a la autoevaluación y a la evaluación externa como instancias orientadoras de las acciones y políticas de nuestra universidad y, en concordancia con los últimos informes que han surgido, será preciso diseñar indicadores -cualitativos y cuantitativos- de impacto de acciones institucionales, ya que esta información nos permitirá dar cuenta, tanto de nuestros logros, como de aquellas cuestiones pendientes de resolución.

\section{Bibliografía}

Bell, Daniel (2001) El advenimiento de la sociedad post-industrial. Un intento de pronosis social. Madrid. Alianza Editorial (original norteamericano 1973).

Castells, Manuel (1998). La era de la información. Economía, Sociedad y Cultura. Vol.3 Fin de Milenio. Madrid, Alianza Editorial.

Castells, Manuel (1996). La era de la información. Economía, Sociedad y Cultura. Vol.1 La Sociedad Red.. Madrid, Alianza Editorial.

Castells, Manuel (1998). La era de la información. Economía, Sociedad y Cultura. Vol.2 El poder de la identidad. Madrid, Alianza Editorial. 1998

Publicado en formato digital: Dra. Lic. Liliana Ramírez. LOS DESAFÍOS DE LA UNIVERSIDAD EN LA SOCIEDAD DEL CONOCIMIENTO. Revista Geográfica Digital. IGUNNE. Facultad de Humanidades. UNNE. Año 11. № 21. Enero - Junio 2014. ISSN 1668-5180 Resistencia, Chaco.

En: http://hum.unne.edu.ar/revistas/geoweb/default.htm 
Krüger, Karsten (2006). El concepto de sociedad del conocimiento. Biblio 3W. Revista bibliográfica de geografía y ciencias sociales (Serie documental de Geo Crítica). Universidad de Barcelona. Vol. XI, no 683.

Morin Edgar (1999). Los siete saberes necesarios para la educación del futuro. UNESCO.

Tünnermann Bernheim, Carlos y De Souza Chaui, Marilena (2003). Desafíos de la Universidad en la Sociedad del Conocimiento. Cinco Años Después de la Conferencia Mundial sobre Educación Superior. UNESCO.

UNESCO (2009). Documento final de la Conferencia sobre Educación Superior.

\footnotetext{
i Castells, Manuel, La era de la información. Economía, Sociedad y Cultura. Vol.1 La Sociedad Red.. Madrid, Alianza Editorial. 1996

Castells, Manuel, La era de la información. Economía, Sociedad y Cultura. Vol.2 El poder de la identidad. Madrid, Alianza Editorial. 1998

Castells, Manuel, La era de la información. Economía, Sociedad y Cultura. Vol.3 Fin de Milenio. Madrid, Alianza Editorial. 1998.

ii Karsten Krüger, El concepto de sociedad del conocimiento. Biblio 3W. Revista bibliográfica de geografía y ciencias sociales (Serie documental de Geo Crítica). Universidad de Barcelona. Vol. XI, nº 683, 25 de octubre de 2006.

iii Karsten Krüger, op.cit
} 